\title{
Zacatecas, entre la vorágine de las violencias y el despojo Jorge Alejandro Vázquez Valdez*
}

\author{
En el ámbito del proyecto neoliberal, y en contraparte al discurso del actual gobierno \\ federal que promueve la entrada de grandes capitales foráneos bajo la promesa \\ del desarrollo nacional, brota actualmente en el país una multiplicidad de violencias \\ de orden estructural, simbólico y criminal que se conjugan para agudizar la descomposición \\ social y propiciar la migración forzada de amplias capas poblacionales. A este escenario \\ Zacatecas se suma como expulsor de mano de obra y como espacio idóneo para \\ la extracción indiscriminada de minerales, al tiempo que el gobierno estatal se mantiene \\ indiferente ante la situación de despojo que se lleva a cabo.
}

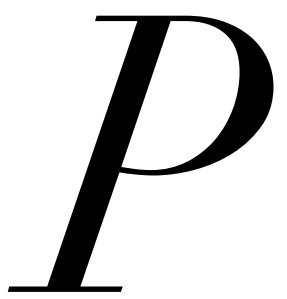

ESE AL DISCURSO oficial que por más de 3 o años pretende justificar el modelo neoliberal en México, el cual presuntamente conduciría a una nueva etapa de mejora social y crecimiento económico, lo cierto es que el país enfrenta una sistemática descomposición social caracterizada por la violación de los derechos humanos y la degradación de las condiciones de vida. Dicho esquema neoliberal, derivado de los postulados del Consenso de Washington, ha sido consistente en dejar a México en una posición

* Estudiante del Doctorado en Estudios del Desarrollo de la Universidad Autónoma de Zacatecas, México. subordinada con el exterior, particularmente con Estados Unidos; privilegiar al libre mercado desde un basamento de acuerdos internacionales inequitativos y con miras a expoliar recursos naturales y trabajo vivo; priorizar la amalgama de intereses nacionales y supranacionales que ponen el beneficio privado sobre el bien común, al tiempo que se guían por la premisa de la obtención de ganancia a toda costa; perpetrar el acotamiento del Estado benefactor y relegarlo a una posición de agente secundario, desde la que cumple la triple tarea de generar condiciones favorables para las operaciones de los grandes capitales, ejercer coerción y aplicar medidas punitivas sobre la disidencia, $\mathrm{y}$ adoptar la desgastada pero recurrente fórmula de socializar las pérdidas y privatizar tanto ganancias como sectores estratégicos para la genera- 
ción y reparto discrecional de excedente. En este escenario la seguridad alimentaria, educativa, sanitaria y medioambiental se ven cuarteadas, lo que propicia que extensas capas poblacionales supuren necesidad, inconformidad y franca desesperación a partir de que el modelo neoliberal funge no como un motor de desarrollo y bienestar, sino como una matriz de violencias sistémicas, entre las que se cuentan la exclusión social, la carencia y precarización del trabajo, la falta de oportunidades educativas, el despojo de medios de producción y subsistencia y la depredación del ambiente. Como fermento de dicha problemática surge en 2006 la "guerra contra el narco", cuya violencia criminal (en conjunto con la manipulación y férreo control de la información por el gobierno) resulta un distractor muy eficaz para que las violencias sistémicas pierdan visibilidad, además de que no hay incompatibilidad entre este tipo de violencia y las de corte estructural - particularmente con sus efectos negativos - lo que conlleva el robustecimiento de la anomia social.

\section{LOS ENTRETELONES}

\section{DE LA MIGRACIÓN FORZADA}

En contraste con la postura del Gobierno Federal mexicano de que la migración es un tema que se atiende en materia de derechos humanos, ${ }^{1}$ y que los cinco ejes del actual Plan Nacional de Desarrollo (PND) son efectivos para contrarrestar los elevados índices de ex-

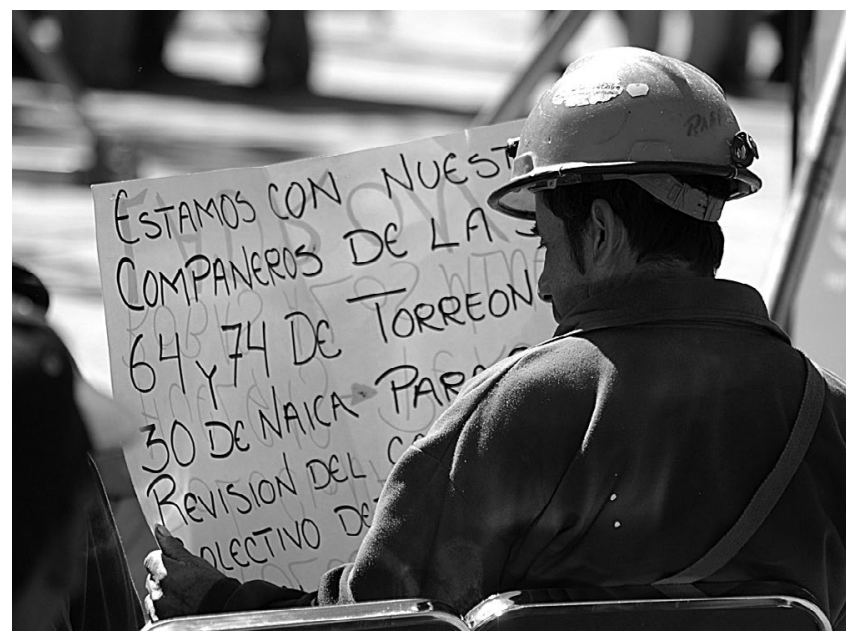

La precarización del trabajo, junto al desempleo, la informalidad y la migración, configuran una de las expresiones más lacerantes

de la inseguridad humana.

Foto: Alfredo Valadez. clusión, inequidad, pobreza y violación de derechos - los cuales contribuyen para el desplazamiento obligado de personas - , lo cierto es que el fenómeno migratorio en México "encuentra su explicación más profunda en la estrategia de acumulación por despojo cuyo propósito es desmantelar el modo de vida y trabajo del sector social, rural y urbano, para ensanchar los ámbitos de valorización de las grandes corporaciones". Las correas de transmisión de dicha valorización son reforzadas en el mundo del trabajo con el sometimiento de contratados o subcontratados al aumento en tiempo e intensidad de la jornada laboral, además de que el esquema se refuerza en el marco de la reciente reforma laboral con el outsourcing y la flexibilización del despido. A esto se suma el adelgazamiento del ingreso y el aumento de precios: los primeros i5 días de 20I4 se incrementó I2.3 por ciento el costo de la canasta básica, alcanzando, de acuerdo a la Procuraduría Federal del Consumidor (Profeco), los ı6o.9o pesos, ${ }^{3}$ y en contraste el salario mínimo registró un incremento a inicios de 20I4 de apenas 3.9 por ciento, lo que representa un ingreso diario de 63.77 pesos para la zona A y 63.77 pesos para la B. ${ }^{4}$ Por su parte, la Organización Internacional del Trabajo (OIT) calificó de preocupante la escasa generación de empleo formal en el país, y asegura que al menos hasta 2016 no aumentará de manera significativa. ${ }^{5}$

De manera paralela al embate contra los trabajadores, se perpetra una indiscriminada apropiación de bienes con la ola de privatizaciones surgida a la par del

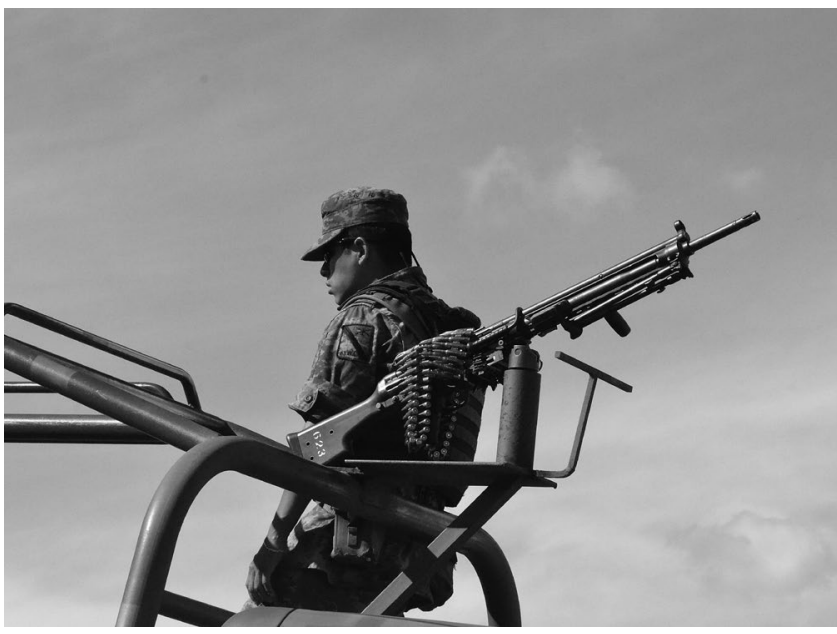

La estrategia de militarización como contenedor de la inseguridad sólo acomete una parte del problema, la criminalidad, pero aumenta la espiral de violencia armada $y$ dispara la comisión de múltiples delitos. Foto: Jorge Vázquez. 


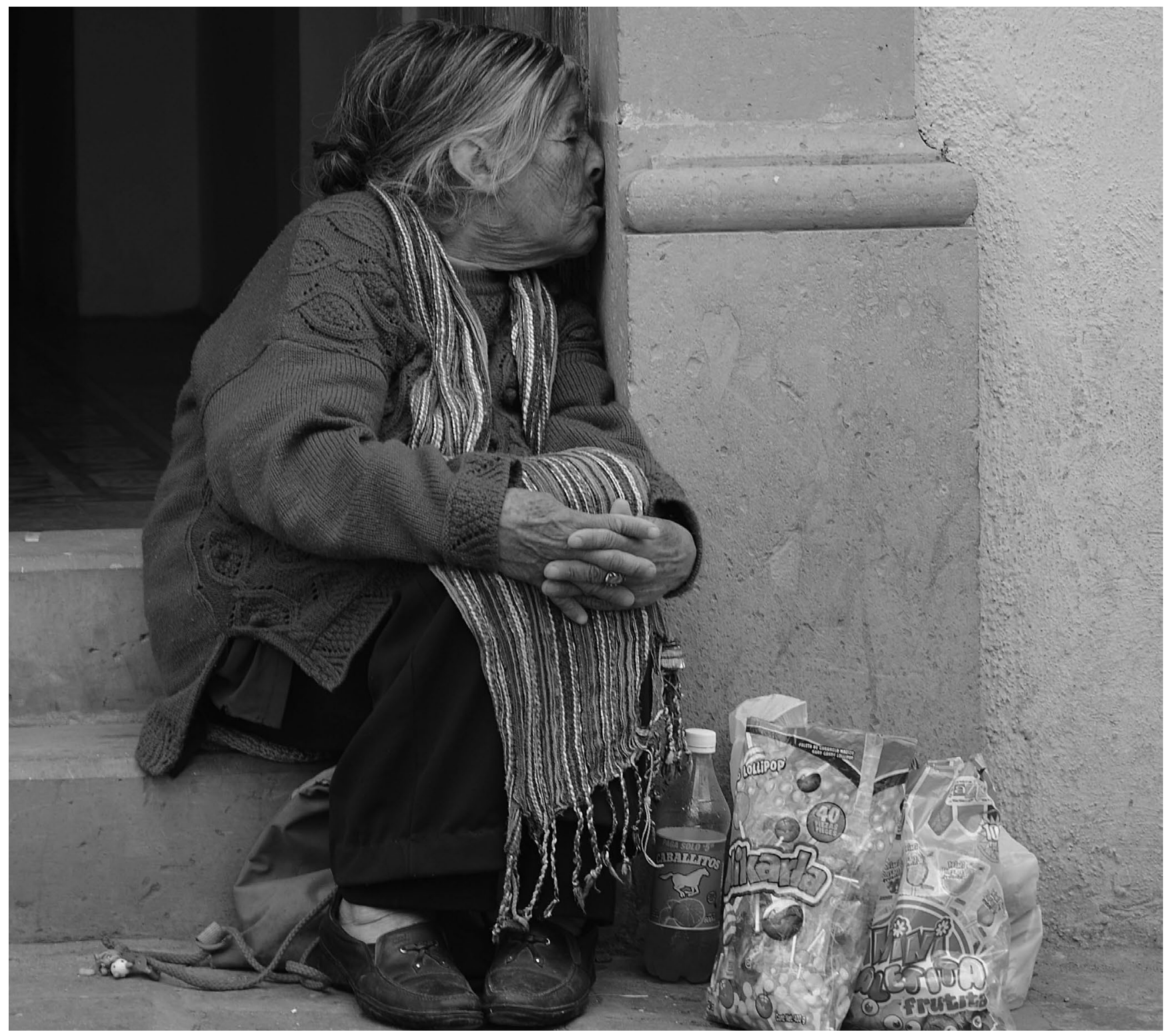

La pobreza asociada a la precarización del trabajo y el deterioro de la calidad de vida es un fenómeno que se ha generalizado sin que las políticas oficiales se propongan cambiar las estructuras económicas para revertirla, sólo se aplican medidas paliativas. Los ancianos sin pensión y enfermos afrontan las perores condiciones.

$$
\text { Foto: Jorge VAzquez. }
$$

modelo neoliberal, la cual ha dado pie a ampliar la brecha entre necesitados y ricos: la Comisión Económica para América Latina y el Caribe (Cepal) informó que 6o.6 millones de mexicanos se ubican debajo de la línea mínima de bienestar, ${ }^{6}$ en contraste con la posición número ocho que Credit Suisse dio a México entre los países con mayor número de ricos, que se estima serán 87 mil para 20r8, lo cual se traduce en que las grandes fortunas se concentran en o.I4 por ciento de la población.? Los problemas derivados de la acumulación por despojo se agudizan con la falta de oportunidades: México ocupa el tercer lugar entre los miembros de la Organización para la Cooperación y Desarrollo Económicos (OCDE) con el porcentaje más elevado de jóvenes que no estudian ni trabajan, alcanzando siete millones $;{ }^{8}$ con la falta de atención médica: 42 por ciento de los habitantes de los 125 municipios más pobres del país no tienen ese servicio, ${ }^{9}$ y desde 2010 el Consejo Nacional de Evaluación de la Política de Desarrollo Social (Coneval) advirtió que 40.7 por ciento de los mexicanos (43.4 millones) no tenía acceso a programas de salud pública o privada: ${ }^{\circ}$ con la inseguridad alimentaria, la cual hasta 2013 era pa- 



La violencia criminal se ha multiplicado en los últimos años: narcotráfico, secuestros, robos, extorsiones,

homicidios, narcobloqueos, entre otras acciones que colapsan la vida cotidiana.

Foto: Jorge VÁzQuez.

decida por 5ı.5 millones de mexicanos." Esto se ha tratado de mitigar recientemente con paliativos de gran calado como la Cruzada contra el Hambre o el Seguro Popular, pero tampoco han erradicado o disminuido significativamente el problema. Bajo la lógica de la matriz de violencias sistémicas antes descrita, las víctimas de esta realidad que terminan por migrar no lo hacen de manera voluntaria, sino bajo la modalidad de una "migración forzada", ${ }^{12}$ que tiene su germen en los sectores más vulnerables. De acuerdo al último censo poblacional del Instituto Nacional de Estadística Geografía e Informática (INEGI), entre 2005 y 2010 un promedio diario de 609 mexicanos abandonó el país para buscar mejores condiciones de vida en Estados Unidos; casi 4o por ciento habitaba las localidades más pequeñas del país y de ellos 250 eran adolescentes y jóvenes de entre i5 y 24 años de edad, y se calcula que 59 mil $6 r 5$ niños de entre I4 años y recién nacidos también cruzaron la frontera. ${ }^{33}$

El concepto de migración forzada está dotado de una perspectiva tripartita que permite $a$ ) diferenciar desplazamientos forzados - ya sea por pobreza, catástrofes naturales o violencia criminal - y los que obedecen a causas de corte voluntario - como matrimonio u oportunidades laborales -; b) funge como norte para dimensionar los motivos estructurales que operan como fermento para generar migración forzada; $c$ ) alienta a dilucidar las intenciones que originan las políticas de atención al fenómeno de la migración. El recuento de afectaciones sociales realizado en párrafos anteriores está guiado por el inciso b, pero para complementarlo es necesario hacer notar que los migrantes mexicanos que se desplazan de manera forzosa - en especial por la pre- cariedad de sus condiciones de vida - hacia el norte con la intención de buscar un mejor futuro en Estados Unidos enfrentan actualmente una política nacional deficiente en el tema y alineada al proyecto de reforma migratoria que une tres eslabones: la criminalización de indocumentados con base en la doctrina de seguridad nacional; una política de detenciones y deportaciones que representa una limpia étnica previa a la reforma migratoria, y el discurso xenófobo que construye enemigos externos (inmigrantes, terroristas y narcotraficantes) provenientes del sur o de oriente. ${ }^{14}$ Así, el migrante que parte de su territorio a raíz de las violencias sistémicas enfrenta un segundo momento de adversidad con esta política de represión y auténtico filtro racial, el cual no se guía por los principios de respeto irrestricto a los derechos humanos tan pregonados por los presidentes Barack Obama y Enrique Peña Nieto, sino por la idea de raza que "organiza la población mundial en un orden jerárquico de personas superiores e inferiores que se convierte en un principio organizador de la división internacional del trabajo", ${ }^{5}$ y desde la cual se decide el ingreso de migrantes y su posterior incorporación a circuitos de producción en los que lejos de situarse en un plano de equidad o al menos respeto y valoración de su trabajo, "quedan relegados a desplazamientos translocales, a espacios de reproducción localmente situados y restringidos, incluso expuestos a diversas formas de segregación territorial" ${ }^{16}$

Esta realidad que conjuga un desplazamiento forzado a raíz de las violencias sistémicas, y la posterior exclusión o segregación de migrantes en Estados Unidos, es sumamente relevante para Zacatecas, en tanto en esta 


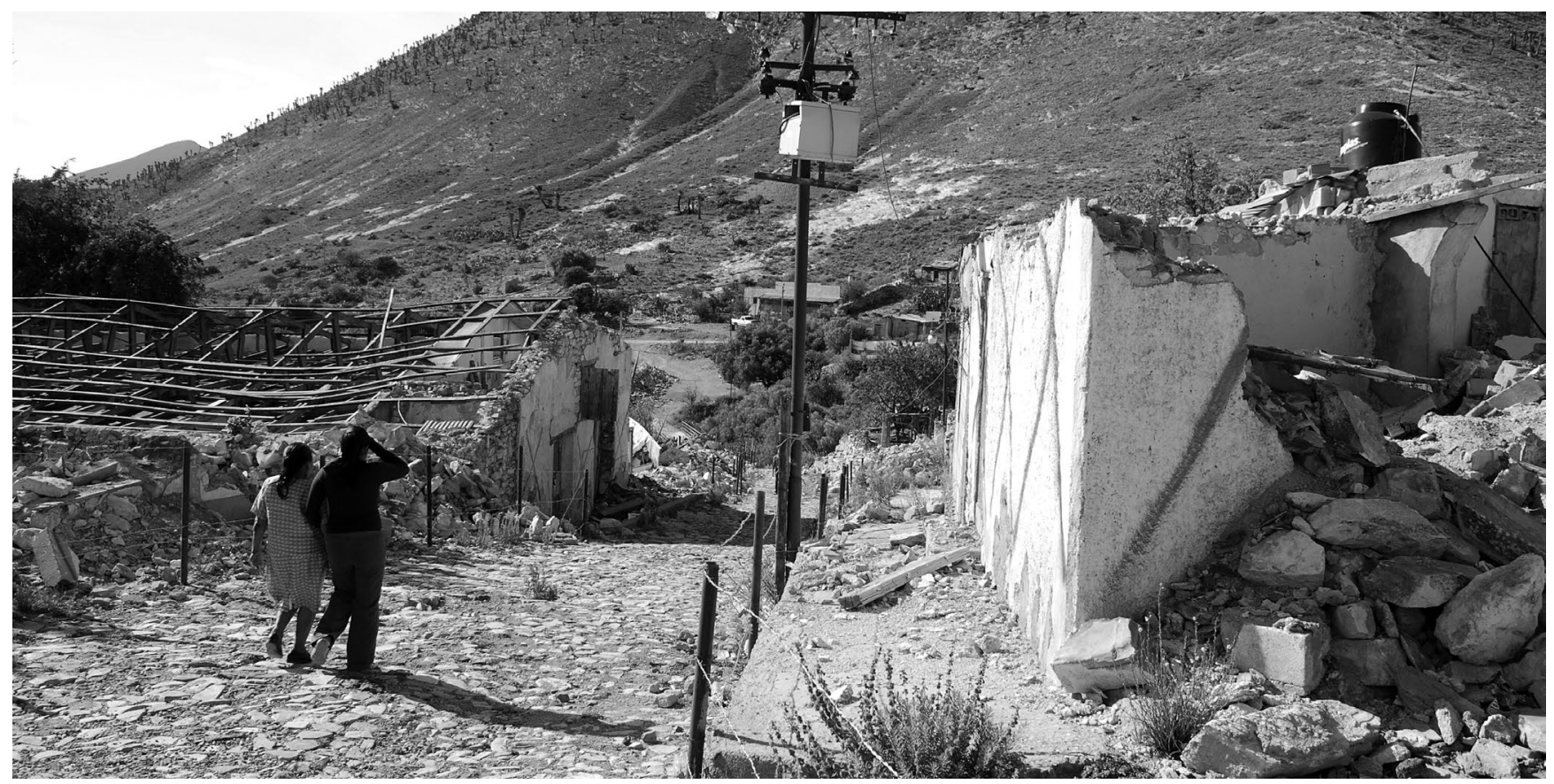

Habitantes de la localidad de Salaverna, Mazapil, Zac., fueron desalojados por presiones políticas y detonaciones subterráneas para permitir que la minera Tayahua, propiedad de Carlos Slim, pudiese extraer minerales del subsuelo.

Foto: Alfredo Valadez

entidad mexicana hay 835 mil 500 personas en pobreza, lo que equivale a más de la mitad de la población, según el Coneval; ${ }^{17}$ el desempleo alcanza a más de 25 mil personas y la informalidad laboral aumentó, entre 2012 y 2013 , de 65.5 por ciento a 67.8 por ciento entre la población ocupada. ${ }^{8}$ Hay más de roo mil jóvenes que no estudian ni trabajan, ${ }^{19}$ y uno de cada cuatro niños no tiene acceso a atención médica, según el Fondo de las Naciones Unidas para la Infancia (UNICEF, por sus siglas en inglés)..$^{\circ \mathrm{A}} \mathrm{A}$ la par, cerca de un millón 800 mil zacatecanos radican en Estados Unidos de acuerdo al INEGI, ${ }^{21}$ y la situación de miles de familias zacatecanas se complica a partir de que la migración a Estados Unidos ha sufrido una drástica caída por la reducción en la demanda de trabajadores, y porque Zacatecas queda limitado a una "estructura económica que no evoluciona hacia la industrialización de sus productos, de ahí que tienda a empequeñecer su capacidad de absorción de fuerza laboral, principalmente de trabajo asalariado". ${ }^{22}$

La tentativa del presente gobierno estatal por modificar esta problemática no transgrede los márgenes del modelo neoliberal y la lógica peñanietista, la cual ha conducido, en el marco de la guerra contra el narco, al uso del presupuesto estatal para montar bases militares, mismas que no han terminado con el problema del narcotráfico, las balaceras o la extorsión a la ciudadanía, y por el contrario han sumido a la población en una notable violencia simbólica a raíz de los intensos operativos armados. A la par se mantiene una política de promocionar y privilegiar a los grandes capitales en detrimento de la dinamización de sectores estratégicos, lo cual se traduce en la llegada de maquiladoras foráneas en búsqueda de mano de obra barata e impuestos ínfimos; la instalación de centros comerciales que generan empleos precarios y afectan directamente a los pequeños comerciantes locales; la imposibilidad del sector agropecuario de competir en mercados dominados por los monopolios - lo cual se ha acentuado en el marco del Tratado de Libre Comercio de América del Norte (TLCAN) - , y la extracción indiscriminada de recursos minerales. El último punto es emblemático, pues el enorme patrimonio minero ha servido sobre todo para enriquecer a actores externos y privados, pero no como motor de desarrollo para la entidad. Esta realidad se complejiza cuando estos problemas se tocan, como a continuación se verá, en un caso que conjuga entrada de capitales, extractivismo y migración forzada a nivel interno.

\section{LA ANTESALA DEL INFIERNO}

Salaverna, ubicado en el municipio de Mazapil, Zacatecas, y cuyo significado es "La antesala del infierno", cobró re- 
levancia en el plano nacional en 2012 debido a la negativa de la mayoría de sus habitantes - campesinos en su mayoría - para ser reubicados a nuevos domicilios por la minera Frisco Tayahua del grupo Carso, propiedad del magnate Carlos Slim. Debido a las proyecciones de la empresa de que en el subsuelo de la zona, específicamente debajo de las casas de los habitantes, existe un yacimiento importante de oro, plata y zinc, la minera edificó en pocas semanas una unidad habitacional con casas de interés social para reubicar en las cercanías a los pobladores, los cuales se negaron bajo el argumento de que las nuevas viviendas no sirven para sustituir las parcelas y corrales que tienen en sus fincas, lo que implica acabar con sus medios de subsistencia. La respuesta de la minera incluyó el inicio de detonaciones - sin previo avisopor las noches en el subsuelo, lo que afectó drásticamente las viviendas de los disidentes, mismos que interpusieron una denuncia formal. Pese a esto no se generó una investigación seria, y en cambio la minera contó con el apoyo del secretario de gobierno, Francisco Escobedo Villegas, quien atribuyó el hundimiento de viviendas a "la humedad" e instó a los inconformes a aceptar los ofrecimientos de la empresa. Posteriormente, el gobernador Miguel Alonso Reyes inauguró el nuevo fraccionamiento sin que el problema se hubiera resuelto, lo que vigorizó el proyecto de tajo a cielo abierto que incluirá el uso anual de 97 mil toneladas de ácido sulfúrico, el cual es corrosivo y tóxico; 85o toneladas de explosivos de nitrato de amonio y mil 200 metros cúbicos de queroseno. ${ }^{23}$

En contraste con el discurso oficial de que la llegada de este capital generará empleos y desarrollo, y de que los habitantes de Salaverna gozarán de viviendas modernas, lo cierto es que se trata de un desplazamiento forzado bajo la lógica del despojo, que incluye la conversión de derechos de propiedad que benefician a la comunidad en la mercantilización y privatización de la tierra, ${ }^{24}$ lo cual parte del nexo extractivismo-violencia, y se sirve de la coacción y la autoridad política para someter a un grupo social. ${ }^{25}$ Esta amenaza se cierne prácticamente sobre cualquier poblado del territorio estatal que cuente con bienes de esta naturaleza, y encuentra su explicación en un marcado apoyo del ex presidente Carlos Salinas de Gortari a transnacionales mineras - en especial canadienses --, situación que no cambió con la alternancia en el poder federal al arribo del Partido Acción Nacional (PAN), y ahora termina por agudizarse con la complicidad del gobernador Miguel Alonso Reyes y la reforma energética peñanietista, la cual posibilita el saqueo por estos capitales no sólo de la riqueza minera, sino del petróleo y el gas.
RefLeXión FINAL

La realidad de que amplios sectores poblacionales de Zacatecas permanecen sumidos en la pobreza y el atraso a pesar de los enormes recursos minerales con que se cuenta, representa una paradoja que se explica por la política gubernamental que por décadas ha resultado adversa a la población, y por la posición subordinada del país ante la hegemonía estadounidense y los grandes capitales corporativos. El correlato de esto conjuga el desgarre del llamado tejido social y la apropiación indiscriminada de trabajo vivo y recursos naturales, sin embargo, con miras a una posterior reflexión sobre esta complejidad, merece la pena indicar que la problemática tiende a profundizarse por dos razones: la transferencia del daño al medio ambiente por las empresas, lo cual en el caso de Zacatecas ya es visible al menos en el municipio de Mazapil con la minera Peñasquito, de la canadiense Goldcorp, y en lo que toca al desplazamiento humano (tanto de ida a Estados Unidos como de retorno a México) que ahora enfrenta un embate por los grupos criminales, los cuales controlan una multiplicidad de delitos dirigidos específicamente contra migrantes, y entre los que figuran el robo, secuestro y extorsión de familiares, las violaciones y prostitución e incorporación forzadas a las células delictivas.

El panorama es poco alentador, pues la posición de las autoridades - tanto estatales como federales - y los medios de comunicación a su servicio desestiman la problemática en razón de que afecta a los sectores más necesitados, y sólo de manera esporádica a los intereses de los grandes capitales, además de que a nivel nacional las primeras briznas de las reformas de gran calado que ahora se ciernen sobre el país apuntan a que habrá nuevas vueltas de tuerca en lo concerniente a la expoliación de bienes naturales, las violencias sistémicas y simbólicas.

Frente a esto es necesario alentar una reflexión que cimbre la inequitativa relación con el exterior, y que a su vez dé cuenta de la complicidad interna para que esto se lleve a cabo. Desde esta perspectiva, tres objetivos son clave: a) visibilizar a las víctimas de los distintos tipos de violencia que laceran a la población; b) analizar las políticas de corte excluyente y forjadas en criterios raciales; y c) generar contrapesos a los privilegios que los grandes intereses privados mantienen en México. A la voluntad que se sitúa en esta posición, se suma el presente texto. 


\section{$-\operatorname{notas} \cdot-$}

'Georgina Olson (2012), "Peña Nieto se compromete a proteger derechos migrantes", en http://www.excelsior.com. mx/2012/12/I8/nacional/875563 (consultado el I//04/2014).

${ }^{2}$ Humberto Márquez, Raúl Delgado y Rodolfo García (2012), "Violencia e inseguridad en México: necesidad de un parteaguas civilizatorio", en Estudios críticos del desarrollo, Zacatecas, 2012, núm. 2, p. I89.

${ }^{3}$ Paulina Gómez (2014), "En I5 días se elevó I2.3 por ciento la canasta básica", en

http://www.eluniversal.com.mx/finanzas-cartera/20I//impreso/en-ı5-dias-se-elevo-123-la-canasta-basica-ıo75o7.html (consultado el 2I/04/20I/4).

4Carolina Gómez (2013), "Acuerdan aumento de 3.9 por ciento a los salarios mínimos; será de 2.53 y 2.39 pesos”, en

http://www.jornada.unam.mx/20ı3/ı2/ı9/politica/oıonıрol (consultado el I//04/20I4).

${ }^{5}$ Carlos Fernández (2014), "México SA", en

http://www.jornada.unam.mx/archivo_opinion/index.php/ autor/front/15/40899 (consultado el I5/04/2014).

${ }^{6}$ Roberto González (2013), "México es el único país de AL donde creció la pobreza: Cepal”, p. 3I, en http://www.jornada.unam. mx/2013/r2/o6/economia/o3mieco (consultado el rg/o4/2014).

䏠go Elías (2013), "México crecerá... pero en millonarios", en http:/www.elfinanciero.com.mx/archivo/mexico-crecera-pero-en-millonarios.html (consultado el I5/0//20I/4).

${ }^{8}$ Carmen Aristegui (2013), "México tiene 7 millones de 'ninis'; es tercero de la OCDE", en http://aristeguinoticias.com/25o6/ mexico/suman-mas-de-7-millones-de-ninis-en-mexico-ocde/ (consultado el I5/04/2014).

${ }_{9}$ Gabriel Xantomila (2012), "Permanece el rezago en los 125 municipios más pobres del país: estudio", en http:/www.oem. com.mx/laprensa/notas/n26496ı6.htm (consultado el ı6/o//2014).

rolberto Morales (2010), "Sin servicio médico, 43 millones: Coneval", en http:/www.eluniversal.com.mx/nacion/ı 76783 .ht$\mathrm{ml}$ (consultado el I\%/04/20I4).

"Angélica Enciso (2013), "En inseguridad alimentaria, 5ı.5 millones de mexicanos: Coneval", en http://www.jornada.unam. mx/2013/o8/or/sociedad/o35nisoc (consultado el I//0/201/4).

'Humberto Márquez, Raúl Delgado y Rodolfo García, op. cit., p. 189 .

${ }^{13}$ Susana González (2011), "Cuatro de cada to migrantes son adolescentes y jóvenes: INEGI", p. 24, en http://www.jornada. unam.mx/20II/o3/1//index.php? section $=$ economia\&article $=024$ nieco (consultado el ז5/o//201/4).
${ }^{4}$ Humberto Márquez (2013), "El redoble de la migración forzada: inseguridad, criminalización y destierro", en Migración y desarrollo, vol. II, núm. 2I, p. I67.

${ }^{15}$ Ramón Grosfoguel (2006), "La descolonización de la economía política y los estudios postcoloniales: Transmodernidad, pensamiento fronterizo y colonialidad global", en Unsettling Postcolonial Studies: Coloniality, Transmodernity and Border Thinking, 26.

${ }^{16}$ Alejandro Canales, "La migración en la reproducción de la sociedad global", en Migración y desarrollo, vol. II, núm. 2I, p. 9.

${ }^{17}$ Carlos Navarrete (2013), "En pobreza, poco más de la mitad de los zacatecanos", en http://jz.mx/2013/oz/29/en-pobrezapoco-mas-de-la-mitad-de-los-zacatecanos/ (consultado el I5/04/2014).

${ }^{18}$ Raquel Ollaquindia (2014), "Incrementa el empleo informal en Zacatecas”, en http://jz.mx/201//o2/13/incrementa-elempleo-informal-en-zacatecas/ (consultado el r5/0//2014).

'Daniela Infante (2012), "Hay roo mil 'ninis' en Zacatecas: José Haro", en http://ntrzacatecas.com/2012/og/r6/hay-Ioo-milninis-en-zacatecas-jose-haro/ (consultado el rg/o//2014).

${ }^{20}$ Alfredo Valadez (2013), "Sin atención médica, uno de cada cuatro niños zacatecanos: Unicef", en http:/www.jornada.unam.mx/2or3/oz/rg/estados/o32niest (consultado el 2I/04/20I/4).

"Redacción (2013), "Se calcula que un millón 800 mil zacatecanos viven en Estados Unidos: Guadalupe Hernández”, en http:/ljz.mx/2013/ı2/19/se-calcula-que-un-millon-8oo-mil-zacatecanos-viven-en-estados-unidos-guadalupe-hernandez/ (consultado el iz/04/2014).

${ }^{22}$ Miguel Moctezuma (20I3), "La migración internacional de Zacatecas y su relación con el desarrollo y la biodiversidad" (documento de trabajo), p. 3, en http:/estudiosdeldesarrollo. net/administracion/docentes/documentos_personales/r5535CON TINUIDADESRUPTURASMIG.pdf. (consultado el I7/0/20I4).

${ }^{23}$ Alfredo Valadez (2013), "Autoriza la Semarnat explotar cobre a cielo abierto en Zacatecas", en http://www.jornada. unam.mx/2013/12/27/estados/o27niest (consultado el 2I/04/2014).

24 David Harvey (2007), El nuevo imperialismo, Madrid, Akal, р. пा6.

${ }^{25} J$ José Seoane (2012), "Neoliberalismo y ofensiva extractivista. Actualidad de la acumulación por despojo, desafíos de Nuestra América", en Revista Theomai, vol. 26, p. 5, en http://www. redalyc.org/toc.oa? id=124\&numero $=26097$ (consultado el I9/04/2014). 


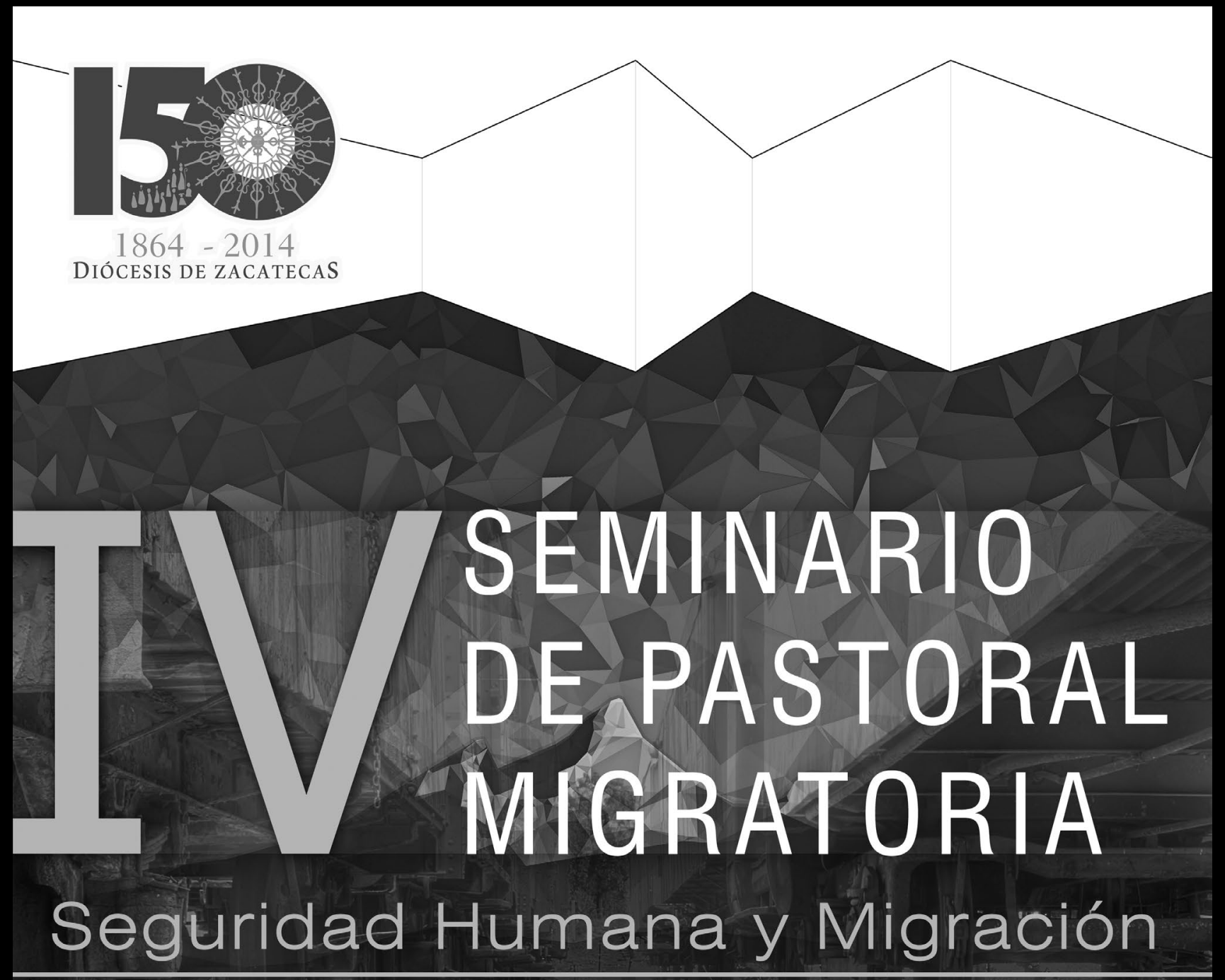

¿Dónde está tu hermano?

(Gen. 4, 9)

\section{4 al $\mathbf{6}$ de Septiembre 2014 9:00 a 19:00 hrs.}

SEDE: OBISPADO DE ZACATECAS,

Miguel Auza \# 219, Centro, Zacatecas

INFORMES: (492) 922 0232, ext. 111

\ pastoralsocialzacatecas@gmail.com

f migrantes zacatecas

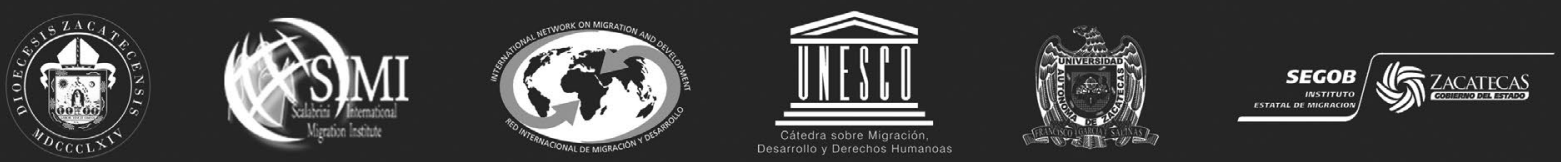

